\title{
News about newspaper advertisers: To what extent can corporate advertising budgets predict editorial uptake and coverage of corporate press releases?
}

\author{
Lischka, Juliane A ; Stressig, J ; Bünzli, F
}

\begin{abstract}
News value theory aims to predict a story's chance of being selected for publication based on news factors and ascribed news values. News values can also predict the coverage of corporate press releases. For news decisions, a newspaper's revenue model may force editors to consider whether the source of a press release is an advertising client, despite the 'separation of church and state'. In addition, for business journalism, corporate press releases have become an increasingly important news source. This study combines news values and advertiser weight to predict news coverage of press releases of banks in the news of partly and fully advertisingfunded newspapers in Switzerland. Results show that advertiser importance can explain press release coverage concerning article length and tone in few cases, but has no universal news value. Public relations material is also not used as editorial subsidy for news. Larger companies are more successful in terms of press release uptake. However, their articles consist of a greater share of non-public relations material. Thus, our findings confirm editorial independence instead of copy-paste or obsequious journalism.
\end{abstract}

DOI: https://doi.org/10.1177/1464884916671157

Posted at the Zurich Open Repository and Archive, University of Zurich

ZORA URL: https://doi.org/10.5167/uzh-131561

Journal Article

Accepted Version

Originally published at:

Lischka, Juliane A; Stressig, J; Bünzli, F (2016). News about newspaper advertisers: To what extent can corporate advertising budgets predict editorial uptake and coverage of corporate press releases? Journalism:1-18.

DOI: https://doi.org/10.1177/1464884916671157 


\title{
News about newspaper advertisers
}

\section{To what extent can corporate advertising budget predict editorial uptake and cov- erage of corporate press releases?}

\begin{abstract}
:
News value theory aims to predict the chance of a story to be selected for publication based on news factors and ascribed news values. News values also predict the coverage of corporate press releases. For news decisions, a newspaper's revenue model may force editors to consider whether the source of a press release is an advertising client, despite the separation of "church and state". In addition, for business journalism, corporate press releases have become an increasingly important news source. This study combines news values and advertiser weight to predict news coverage of press releases of banks in the news of partly and fully advertising-funded newspapers in Switzerland. Results show that advertiser importance can explain press release coverage in few cases but has no universal news value. Thus, our findings confirm editorial independence instead of obsequious journalism.
\end{abstract}

Keywords: Public relations, business journalism, corporate strategic communication, advertising, news value theory, revenue model, 


\section{Introduction}

Journalistic selection of editorial content is driven by news values and affected by economic, organizational, procedural and professional constraints as well as by external groups, such as advertising clients and public relations (PR) professionals (Hanitzsch and Mellado, 2011). For many years, concern has been raised that PR increasingly influences journalistic news, which leads to questions concerning the media's position as the fourth estate (Davis, 2000; Lewis et al., 2008; Jackson and Moloney, 2015). Lewis et al. (2008: 18) find that "News, especially in print, is routinely recycled from elsewhere," particularly from PR material. Especially business journalism relies on information provided by corporate PR. Companies strategically provide an increasing amount of instrumental information to journalists. Press conferences and press releases are main PR instruments for companies to affect news coverage. In the course of decreasing editorial resources, dependency on PR material increases. It has become a routine for journalists to process incoming PR material, what Boyer (2013) refers to as neutral screenwork.

An additional factor potentially increasing the influence of PR on news is when PR material is sent by advertising clients of news organizations. There is a long tradition of research investigating the relation between advertising clients and their coverage, suggesting that advertisers exert influence on the editorial process and thus on editorial con-

tent-instead of just placing their ads next to the news. Increasing economic constraints 
in the media industry caused by decreasing advertising income, particularly for newspapers, intensify such an influence.

The metaphor of the separation of church and state describes the decoupling of editorial content and advertising or PR content in media products. Although the separation of church and state is a strong professional value in journalism, research indicates that the border diminishes (Baerns, 2003; Dix and Phau, 2009). The terms copy-paste journalism or obsequious journalism suggest that this separation is not always followed.

Whether press releases of companies that are also advertising clients are more likely or more positively covered was barely investigated in previous research. In addition, few studies focus on news factors and news values of business news. This study aims to fill these research gaps and examines whether the advertising weight of a company influences press release uptake and coverage in the news. We argue that (1) message characteristics, such as news values of press releases, (2) receiver characteristics, such as news outlets' business models and dependency on advertising revenues, and (3) source characteristics, such as size, resources, and advertising expenditures of a company may diminish the border between church and state, and thus increase the coverage of corporate press releases. Empirically, we combine a content analysis of press releases of Swiss banks and their media coverage in national and regional partly and fully advertising funded daily 
newspapers in Switzerland focusing on investor- and consumer-oriented coverage, complemented with secondary data on each banks' balance sheet total and advertising budget per news outlet.

\section{Background and state of research}

\subsection{PR and business journalism}

PR is an important instrument of strategic corporate communication, which intends to create public awareness, persuade audiences, successfully deal with corporate crises, or build corporate reputation, which may in turn be capital-forming for a company (Kiousis et al., 2007). In order to exert an agenda-building capacity, the most important PR instrument are press releases (Kiousis et al., 2007). Press releases aim at influencing news coverage ,to make sure the story is framed in a way that is consistent with the organization's preferred framing (i.e., how the organization would like to have its story told)“(Cornelissen, 2011: 148).

The relation between corporate public relations and business journalism is described as close, interdependent, fulfilling mutual needs, as well as adversarial due to colliding interests between communication professionals and journalists (Anderson and Lowrey, 2007; Cornelissen, 2011; Pienegger, 2004; Obermaier et al., 2015). The relation can be a win-win division-of-work relation, since information is exchanged for attention of publics. According to Maat and Jong (2013), after all less than half of a news article 
originates from press releases. Against the background of diminishing journalistic staff in news organizations and increasing time pressure in the digital age, PR influence on news increases (Lewis et al., 2008; Reich and Godler, 2014). Jackson and Moloney (2015: 1) reveal that PR material is not only an information source but becomes an editorial subsidy since PR professionals provide "targeted, tailored, page-ready news copy that contains key client messages.” And $40 \%$ of financial news is found to contain PR material compared to $33 \%$ of political news (Reich, 2011).

Yet business journalists often distrust corporate press releases and are aware of PR's persuasion purpose, describing PR actors as "ethically willing to compromise" (Pienegger, 2004: 158). Business journalists evaluate corporate PR as rather uncritical, intrusive, dependent, and neither influential nor ineffectual (Pienegger, 2004: 157). Larsson (2009) reports based on interviews with PR professionals and journalists that "the former claim that they often succeed in planting their promotional ideas in newspapers and programmes, the latter mostly deny such a claim." According to Anderson and Lowrey (2007), journalists try to maintain jurisdiction over their work and defy journalistic norms when another occupation's inference process collides with their professional practices. van Hout et al. (2011: 1884) describe that paraphrasing from press releases enable business reporters to write fast and efficiently, "while using the source material, the journalist is focused on getting round some of the frames offered in it." Hence, while using ready-made parts of press releases, journalists strive to add own contributions to articles. 


\subsection{Advertisers in the news}

The hypothesis of primary orientation states that news organizations more strongly align towards advertisers' requirements than the reader market due to higher advertising than copy price income (Brierley, 2006; Sumner, 2001). Commercialization of news media and economic pressure have increased the dependency of news outlets on advertising income (McManus, 2009; Nyilasy and Reid, 2011). Advertisers often reduce advertising expenditures, especially for print media, during recessions (Picard, 2001; Tellis and Tellis, 2009; van der Wurff et al., 2008). Decreasing advertising income for newspapers enhance the power of advertisers on news making. In this regard, a U.S. newspaper journalist reports as cited in Weaver et al. (2007: 80), "With the economy in such poor shape and advertising revenue down, the company has less resources to put in the news operation. The increasing use of advertorial publications to bulk up advertising and masquerade as news [...] the advertising side generates them because they can sell advertising for them." This anecdotal evidence is quantified in surveys with journalists and advertising directors (De Smet and Vanormelingen, 2011; Nyilasy and Reid, 2011; An and Bergen, 2007).

Advertiser pressure is widespread in newspapers but may be infrequently successful (De Smet and Vanormelingen, 2011; Hujanen, 2009; Nyilasy and Reid, 2011). Instead, journalistic norms such as integrity and self-censorship are more important (Nyilasy and 
Reid, 2011). Advertiser demands are considered up to a certain degree only, because journalists "have to consider the reaction from readers. [...] People in the newspaper business have to think about their circulation," as a journalist reports in Weaver et al. (2007: 80). Yet smaller, chain-owned or local newspapers are found to more likely compromise editorial interests to please advertisers (An and Bergen, 2007).

Content analyses support the hypothesis of primary orientation showing that advertising clients are mentioned more often and more positively in editorial content than non-advertising clients (Choi and Park, 2011; Hagen et al., 2014; Kolb and Woelke, 2010; Reuter and Zitzewitz, 2006; Rinallo and Basuroy, 2009; Gambaro and Puglisi, 2015). Reuter and Zitzewitz (2006) show that financial outlets more depending on fund advertisers more likely recommend financial products of their advertisers than national newspapers less dependent on advertising income of these advertisers. Kolb and Woelke (2010) analyze the media coverage of the Swiss bank UBS during the financial crisis in two free dailies in Switzerland, one gaining advertising income by UBS and one does not. The content analysis reveals that the newspaper relying on UBS' advertising budget avoided negative reporting. It reported about $15 \%$ less often about UBS, used about $25 \%$ less often judgmental quotes and statements, and was less critical in news tone. Kolb and Woelke (2010) conclude that the newspaper not relying on UBS as an advertising client was independent enough to select UBS news and to value UBS autonomously, whereas the dependent newspaper tried to report only what was absolutely necessary in a less critical 
tone. Hagen et al. (2014) analyze the content of two German weekly political magazines for the year 2011. Results reveal a positive relationship between frequency and tone of coverage with the numbers of ad-pages in the magazines. Especially very important advertising clients profit from more frequent coverage and product mentioning. More frequent production mentioning admits the presumption that PR material of advertising clients is used more often by the magazine.

Combined findings on the influence of PR material and advertising on news suggest that advertising may function as an additional selection principle enhancing the coverage of press releases of advertising clients.

\subsection{Advertising expenditures as determinant of news coverage of press releases}

De Smet and Vanormelingen (2011: 17) quote a journalist stating, "Equally baleful is the actual pressure from advertisers who steer the news by press releases that end up unchecked in the newspapers." Yet few studies analyze the combined effect of the success of PR material from an advertising client as source. Based on content analyses of fashion companies' coverage and their advertising budget in consumer magazines in the U.S. and several European countries, Rinallo and Basuroy (2009: 42) conclude that "high levels of product publicity (coverage) are hardly obtainable without significant advertising expenditures," challenging the notion of unpaid news coverage based on PR

material. Yet, Seletzky and Lehman-Wilzig (2010) report that fewer commercial than 
nonprofit organizations' press release succeed, which may be due differences in assumed marketing budgets by journalists: "commercial companies [...] have enough money to pay for advertising their message whereas nonprofits $[\ldots]$ cannot afford to spend financial resources on publishing paid-for announcements." Thus, higher advertising budgets may even prevent PR success.

Choi and Park (2011) and Gambaro and Puglisi (2015) explicitly consider both press releases and advertising budget for news coverage. Choi and Park (2011) compare press releases and the ad-page volume of four major U.S. cellular phone companies and their news coverage in two national (The New York Times and USA Today) and four local Texan newspapers in 2009. Results reveal that press releases of only the most important advertising client are covered more often and with longer articles. In addition, local newspapers had a higher acceptance rate of press releases than national. Whether the article tone was more positive for advertising clients was not tested. Similarly, Gambaro and Puglisi (2015) find for national and regional Italian newspapers between 2006-2007 that news coverage of stock-listed companies in a newspaper increases the day after a press release is published, especially when advertising expenditure is higher for a given newspaper. Although both studies note that newsworthiness is a success factor of press releases, news factors were not included to the analysis. 
These results suggest that the importance of an advertising client determines the newsworthiness of a press release, i.e., the editorial uptake and coverage, along with news values of that press release.

\subsection{Hypotheses and research question}

There are three stages of the journalistic selection of PR material, the selection for the news agenda, the editing decision for more or less investment of journalistic capital, e.g., time for rewriting, and the editorial decision on sizing and placement in the edition (Schafraad and van Zoonen, 2015). In each of these stages, advertising expenditures of the PR material source may play a role. Generally, all three stages may be influenced by (1) message, (2) receiver, and (3) source characteristics that generally predict success of press releases.

\subsubsection{Message characteristics}

Galtung and Ruge (1965) identified news factors awarding newsworthiness to events and issues, which lead to the selection of an event for the news. Eilders (2006: 5) defines news factors as "event characteristics or characteristics of the reality construction by journalists and recipients." Various catalogues of news factors have been studied (Eilders, 2006; Harcup and O'Neill, 2001). Eilders (2006: 11) identifies six news factors repeatedly shown to affect journalistic selection, i.e., relevance/reach, damage/contro- 
versy/aggression/conflict, elite persons/prominence, continuity, proximity, and elite-nation. A news value describes the relevance of a news factor for a story ascribed by journalists (or an audience member) and is reflected in placement, length, and format of an article (Fretwurst, 2008; Kepplinger and Ehmig, 2006). News values are decision guidelines that "are invoked, unconsciously or explicitly, at every step of the news process" (Cotter, 2010: 67).

Shoemaker and Cohen (2006) suggest that PR professionals agree with journalists about news values. That news coverage of press releases increases with news factors and news value has often been affirmed (Choi and Park, 2011; Hong, 2008; Schweiger and Jungnickel, 2011; Seletzky and Lehman-Wilzig, 2010). Schafraad and van Zoonen (2015) analyze the impact on investment of journalistic capital of news factors that are especially relevant for business news, i.e., surprise, controversy, impact/reach, positive and negative consequences, elite and prominent persons, and dynamics/surprise. Results show that the news factor consequences increases journalistic treatment of a press release, i.e., that PR material is not identically adopted. The news factors impact/reach, reference to positive consequences, and controversy increase the use of additional sources. The study did not find effects of the news factors prominence, elites, negative consequences, and dynamics/surprise on journalistic treatment. However, negative consequences and prominence are described as news factors repeatedly shown to affect journalistic selection by Eilders (2006). We expect the following. 
H1. The higher the news factor reach in a press release, the lower the degree of uptake for a news article.

$\mathrm{H} 2$. The higher the news factor positive consequences in a press release, the lower the degree of adoption for a news article.

H3. The higher the news factor negative consequences, the higher the degree of adoption for a news article.

H4. The higher the news factor prominence, the higher the degree of adoption for a news article.

Kiousis et al. (2007) show that certain aspects of corporate press releases are not taken over in a similar way by all news outlets. Kepplinger and Ehmig (2006) demonstrate based on an experiment with journalism students that they ascribe different news values to news factors depending on whether they were asked to make news decisions for a national, regional, and a fictitious tabloid newspaper. Similarly, Cotter (2010) points out that news values are interpreted differently across news outlets. Therefore, we ask the following.

RQ1. How do the effects of news factors vary for press release adoption across national, regional, and tabloid news outlets?

\subsubsection{Receiver characteristics}

Editorial slant and content differentiate among news outlets (Beam, 2003; Hamilton, 2004). Picard (2004: 57) states that "The primary content of newspapers today is 
commercialized news and features designed to appeal to broad audiences, to entertain, to be cost effective and to maintain readers whose attention can be sold to advertisers." Economic constraints vary among news outlets according to their revenue model and determine journalists' selection processes. If copy-paste journalism or obsequious journalism towards press releases of advertising clients exist, these press releases should have a higher chance to become part of the coverage, be covered to a greater extent, more prominently, and more positively. We expect the following.

H5. The stronger a news outlet depends on advertising revenue from a company, the higher is the degree of adoption for a news article.

H6. The stronger a news outlet depends on advertising revenue from a company, the larger is the article size.

H7. The stronger a news outlet depends on advertising revenue from a company, the more prominent is the article placement.

H8. The stronger a news outlet depends on advertising revenue from a company, the more positive is the article tone.

\subsubsection{Source characteristics}

Press releases of commercial sources of various industries and topics are less successful compared to more often covered press releases of nonprofit sources (Schweiger and Jungnickel, 2011; Seletzky and Lehman-Wilzig, 2010). In addition, Anderson and Lowrey (2007) find that source resources, .i.e., a larger organization and dominance of 
the source, increase PR success. "Source organizations with abundant resources and proximity are not only able to provide journalists with useful material, they are also likely to have personnel skilled at establishing relationships with journalists." (Anderson and Lowrey, 2007: 398). Moreover, Davis (2000) shows that corporate elites release increasingly high PR budgets and use PR to gain a competitive advantage over rivals extending their corporate power. Therefore, we propose the following.

H9. The higher the company resources, the higher is the degree of adoption for a news article.

\section{Study}

\subsection{Company and press release sample}

In order to investigate relations between news factors, advertiser importance, and corporate press release coverage, we analyze press releases of companies with different advertising budgets. In order to keep non-measured external influences low, we chose organizations within one industry. We chose the finance sector because it is an important sector for the Swiss economy, consists of players of various sizes and invests considerably but not most highly into advertising compared to other industries. In Switzerland, the finance sector is the top-7 contributor to the total national advertising expenditures and slightly decreased advertising expenditures in 2012 compared to 2011 (Media Focus, 2012). We chose the observation period in 2012, because the severe years of the banking 
crisis were over, the financial sector was part of the news coverage (fög, 2013), and advertising income for press outlets had stagnated in 2010 and 2011 after the 2009 decrease and before decreasing again from 2012 until today (Stiftung Werbestatistik Schweiz, 2016, 2013). We assume that it has been increasingly important for news outlets to maintain their advertising clients since 2009, whereas diminishing personal resources of news outlets lead to an increase of PR influence on news (Lewis et al., 2008; Reich and Godler, 2014). This increasing dependence may lead to a higher willingness for obsequious and copy-paste journalism, especially toward most important advertising clients. Therefore, the observation period may provide a situation in which advertising income matters more to news outlets, whereas our industry selection is more conservative since we did not select one of the top advertising industries.

We analyze the eight largest Swiss banks in terms of balance sheet total in 2012 according to the Swiss National Bank (2014), i.e., UBS (775.7 bn CHF), Credit Suisse (589.1 bn CHF), Raiffeisen Bank (164.7 bn CHF), Julius Bär (54.0 bn CHF), Migros Bank (37.8 bn CHF), Valiant Bank AG (25.1 bn CHF), Union Bancaire Privée (UBP) (18.5 bn CHF), and Bank Coop AG (15.3 bn CHF). Therefore, the sample is biased towards banks with higher resources that are more likely to spend higher advertising budgets and become part of the news coverage than smaller banks. However, balance sheet total and thus the importance of the chosen banks still vary sufficiently. 
All press releases of these banks in 2012, available on the banks' websites, constitute the population from which we sampled the press releases of all odd calendar weeks resulting in a sample of $n=70$ press releases. Therefore, we have a comprehensive selection representing the year 2012 for each bank not focusing on certain events or topics only.

\subsection{News outlet and article sample}

The print news outlets are chosen based on a high reach within the German-speaking area of Switzerland, varying editorial slant and revenue model. We chose the national quality newspaper Neue Zürcher Zeitung (NZZ), the regional newspaper Tages-Anzeiger $(T A)$, and the free tabloid evening newspaper Blick am Abend $(B a A)$. The former two are partly financed through advertising and subscriptions, the latter one solely through advertising. According to Mediafocus data, NZZ realizes a total gross advertising income of 51.9 m CHF, TA 82.8 m CHF, and BaA 44.8 m CHF in 2012. NZZ focuses on multi- and international hard news (fög, 2013: 244-245). The business section is the largest section in NZZ. More than three quarters of the business articles are editorial (fög, 2013: 244). Following sports and culture, the business section is the third largest section in $T A$ with more than one third editorial copy (fög, 2013: 254). TA also focuses broadly on multiand international hard news (fög, 2013: 255). $B a A$ focuses on entertaining news. It has no business section, however, a business editor-in-chief. 
We searched for articles containing the banks' names within these news outlets in the Swiss data base "Schweizer Mediendatenbank AG (SMD)" that functions as archive for major Swiss publishing houses. All articles containing the banks' names on the same day (only relevant for the evening newspaper $B a A$ ) up to three following days of a press release publication date are collected and coded, resulting in $n=674$ articles of which $n$ $=153$ refer to a press release. That is, about $23 \%$ of the articles contain "recycled" material from the press releases. On average, one press release $(n=70)$ resulted in two articles. The minimum qualifying criterion for "article refers to press release" was the adoption of the specific topic of the press release in own terms and phrases.

$N Z Z$ and $T A$ covered eight whereas $B a A$ only covered four out of ten press releases. Table 1 contains an overview over the covered press releases per bank and news outlet.

[Insert Table 1 about here]

Table 2 shows the banks' relative advertiser importance for each news outlet. For NZZ, the big bank Credit Suisse is by far the most important advertising client, followed by Julius Bär and UBS. For TA, banks are less important advertising clients, with Julius Bär being the most important one, followed by Credit Suisse and UBS. BaA is least dependent on advertising income from the banking sector with Raiffeisen Bank being the most important client.

[Insert Table 2 about here] 


\subsection{Measurement and coding}

News factors of press releases are measured based on previous news value studies (Eilders, 2006; Seletzky and Lehman-Wilzig, 2010; Maier and Ruhrmann, 2008; Schafraad et al., 2015). Reach refers to the number of persons taking part in an event or being affected by an event. Zero reach is coded if no persons are directly affected, low reach if single persons or small groups are affected, medium reach if social categories such as employment or interest groups are affected, such as bankers, managers, students, citizens of cities or regions, workers, foreigners etc. High reach is coded if all citizens of a country or other nations, the society or the state are affected. Positive and negative consequences are positively or negatively framed events or their consequences as uses or success and damage, respectively. Following Eilders (1997), we distinguish material, ideal, and existential consequences. We code no positive or negative consequences when no uses or success and damage is mentioned, respectively. We code low positive or negative consequences if only material consequences such as increase or decrease of standard of living, wages, social benefits, and gaining or losing property or money are mentioned, respectively. Medium positive and negative consequences relate to ideal uses or damage, such as stabilizing or improving and endangering or worsening the financial system, security, company image, or activities saving and damaging the environment, respectively. High positive and negative consequences are coded when uses for essential human or 
corporate needs such as increasing and decreasing long-term freedom, health, life expectancy or employment creation are mentioned, respectively. Prominence is measured as degree of publicity of a person. Therefore, we code the number of references to certain persons in articles and ascribe no prominence for 0 to 9 references, low prominence for 10 to 19 , medium prominence for 20 to 29 , and high prominence for 30 or more references per person.

On article level, the degree of adoption is measured as percentage of complex phrases, sentence fragments or whole sentences of the press release appearing also in the article. That is, if an article uses fragments of the first sentence and a pseudo-quotation from the press release, these parts are counted in relation to the non-adopted parts of the press release. However, adopting a source from the press release was not weighted more strongly than adopting phrases or fragments. If a press release is adopted word by word, the degree of adoption is $100 \%$. Article size is the word count per article. Placement refers to the page number on which the article was published. Tone is measured as negative $(-1)$ when the bank is predominantly criticized, as neutral (0) when no clear tone is held or negative and positive judgments are made, and as positive (1) when predominantly positive aspects are mentioned.

Coding was performed by two trained coders reaching a satisfying Krippendorff's Alpha for the press release coding, i.e., reach (0.991), positive consequences $(0.774)$, 
negative consequences (0.783), and prominence (1.0), and the article coding, i.e., degree of adoption (0.996), article size (0.901), placement (0.925), and tone (0.733).

\section{Results}

NZZ adopted $15 \%$ of press release material in their articles on average, TA $12 \%$, and $\mathrm{BaA} 6 \%$. Articles are longer and placed further back in NZZ (415 words; page 32) and TA (443 words, page 33) than in $B a A$ (216 words; page 7), which is due to the structure of the hard news and tabloid newspaper, respectively. Article tone is neutral in $N Z Z$ articles (-.03) and slightly positive in $T A(-.25)$ and $B a A(-.24)$.

For H1 to H4, we test the press releases' news factors controlling for advertiser importance for each news outlet and balance sheet total of the source. Overall, results in Table 3 reveal rare influences of news factors as selection criterion. Reach does not negatively affect the degree of uptake. Therefore, we reject H1. For TA, if more people are affected, an article increases by 124 words. Positive consequences tend to negatively affect degree of adoption in a $T A$ article. With higher positive consequences, the adoption of press release material decreases $7 \%$. Therefore, we partly accept $\mathrm{H} 2$. Negative consequences positively affect the degree of adoption of press releases in a $N Z Z$ article. $N Z Z$ adopts $7 \%$ more of a press release if higher negative consequences are mentioned. Hence, we partly accept H3. Prominence positively affects adoption in a $B a A$ article. When more 
prominent the people mentioned in a press release, $B a A$ adopts $3 \%$ more of a press release. Thus, we partly accept $\mathrm{H} 4$.

Related to RQ1, each news outlet seems to follow its own logic when it comes to news factors as selection criterion. Negative consequences increase the degree of a press release to be covered for NZZ. Reach increases the coverage for TA. Prominence increases the coverage for $B a A$.

For $\mathrm{H} 5$ to $\mathrm{H} 8$, Table 3 shows that advertiser importance rarely affects article characteristics, controlling for press release news factors and source resources. For none of the outlets, advertiser importance affects the degree of adoption of press releases or placement. Therefore, we reject $\mathrm{H} 5$ and $\mathrm{H} 7$. For $T A$, a $0.01 \%$-increase in relative advertiser importance of a client, which is equivalent to CHF 828k (ca. USD 900k in 2012) for TA, would increase the article size resulting from a press release of that client by almost 500 words. This would be almost twice the advertising budget the most important banking sector advertiser spends for $T A$. There are no effects for $N Z Z$ and $B a A$. Therefore, we partly accept H6. For $B a A$, a $0.002 \%$-increase in advertiser importance, which is equivalent to CHF 90k (ca. USD 98k in 2012), tends to increase the tone of articles from neutral to positive. This amount is approximately what the most important banking sector advertiser spends for $B a A$. Hence, we partly tolerate $\mathrm{H} 8$.

Table 3 reveals that source resources are most often influencing whether and how a press release is covered. Balance sheet total, which is also a proxy for the importance 
of the source, decreases the degree of adoption of articles of the two quality outlets $N Z Z$ and TA. Therefore, we reject H9. Thus, the editorial effort increases with increasing importance of a source for the two quality newspapers. The larger the company, the larger the article for all three news outlets and the more prominently the article is placed for $T A$ and $B a A$. Only the article tone does not depend on source resources.

[Insert Table 3 about here]

\section{Discussion}

In total, about every fifth article about a bank refers to press releases, which is considerably lower than the $40 \%$ share for financial news found by Reich (2011). Whereas between almost half up to $80 \%$ of the press releases result in news, not more than $15 \%$ of press release text are adopted for an article on average. Hence, journalists access additional material, invest extra journalistic work and PR material does not solely influence coverage. Although larger companies may have higher PR budgets and professional resources to provide journalists with useful PR material, and press releases of bigger players are frequently reported, journalists increase their effort when reporting about big companies. Thus, higher source resources increase PR success as found by Anderson and Lowrey (2007) — in terms of press release uptake. However, the articles themselves consists of a greater share of non-PR material.

Compared to the importance of the source, press release news factors and advertiser importance are weak predictors of corporate press release coverage. We did not find 
one news factor being a constant selection criterion for all three news outlets. The national quality newspaper uses negative consequences and the tabloid prominence as criteria for editorial uptake, which is line with journalistic selection criteria reported by Eilders (2006). That is, negative consequences and prominence lead to "recycling" from PR material, in the words of Lewis et al. (2008). However, page-ready news copy from press releases, as described by Jackson and Moloney (2015), has not been extensively used by the news outlets in this study. Positive consequences tend to decrease the degree of uptake for the regional outlet. Press releases with positive consequences are either not selected by the regional outlet or increase journalistic treatment as reported by Schafraad and van Zoonen (2015). Besides reach that increases article size at the regional newspaper, no further news factors are identified affecting article size, placement or tone.

We agree with Shoemaker $(2006: 105,110)$ stating that because newsworthiness is "a cognitive construct, a mental judgment," it "can only marginally predict what actually becomes news". Hence, each news outlet follows own news values, as suggested by Cotter (2010), Kiousis et al. (2007) or Kepplinger and Ehmig (2006).

In rare cases, advertiser importance can be regarded as news value. Advertiser importance increases the article size in the regional newspaper. The regional newspaper is more likely to consider advertisers' press releases than the national, as suggested by An and Bergen (2007). This is in line with findings by Choi and Park (2011) showing that important advertising clients are covered with longer articles in regional newspapers. 
However, more than USD 900k, which is almost double the amount the most important advertiser spends for the outlet, would be necessary to increase articles by 500 words. In line with Kolb and Woelke (2010) and Hagen et al. (2014), we find that advertising clients tend to be more positively covered — but this is only valid for the tabloid newspaper. It takes about USD 100k for an increase from negative to neutral or neutral to positive tone. This can be interpreted as sign of commercialization and economic pressure increasing the dependency on advertising clients as described by McManus (2009) or Nyilasy and Reid (2011). Yet since the tabloid is least dependent on advertising from the banking sector compared to the national and regional outlet, the effect of advertising importance may increase when investigating an advertising industry that is more important, such as the food or telecommunication industries.

In sum, the lack of negative effects of advertising budget on press release uptake or coverage show that higher advertising budget does not prevent PR success, as proposed by Seletzky and Lehman-Wilzig (2010). Yet significant advertising spending does not lead to high levels of press release coverage either, as suggested by Rinallo and Basuroy (2009).

\section{Conclusions and limitations}

Advertiser importance can sometimes function as distinct selection criterion for corporate press releases. It increases article size in regional and improves article tone in tabloid news outlets. However, similar to the studied news factors, advertiser importance 
has no universal news value. Thus, news about newspaper advertisers is not generally more frequent or longer, more prominently placed or more positively in tone.

Since in total only every fifth article about the companies takes up a press release topic or contains material from press releases, journalists do not recycle routinely from press releases.

We conclude that the separation of church and state diminishes in few cases only. But we stress that we did not find evidence for expansive obsequious journalism. The studied news outlets do not "bulk up advertising [and press releases] and masquerade as news" (Weaver et al., 2007: 80). We also do not find that PR material is an editorial subsidy for news about the banking sector. Journalists seem to employ primarily neutral screenwork (Boyer, 2013) instead of copy pasting press releases. We cannot conclude that high levels of publicity depend on significant advertising expenditures, as argued by Rinallo and Basuroy (2009). Instead, high levels of publicity depend on company importance and are thus reached by larger players, which is in line with Anderson and Lowrey's (2007) and Davis (2000) findings; Corporate elites obtain power over the news agenda — independently of their advertising importance to a news outlet. For large companies, PR exerts an agenda-building capacity as means strategic corporate communication.

Overall, the results hint at editorial independence from advertising clients, also in times of diminishing advertising income and editorial resources. That is, business news 
reporting follows the professional journalistic value of separating church and state - at least when it comes to the banking sector.

Our results refer to advertising clients from a medium strongly investing advertising industry and may not generalizable to clients from more important advertising industries, which also Reuter and Zitzewitz (2006) imply. In addition, the selected advertising clients had a low variance of advertiser importance per news outlet. With attributing 7\% to the total advertising income of the national news outlet, the bank Credit Suisse was relatively the most important advertising client in our sample. For the selection of advertising clients, future studies should compare between major and mediocre advertising industries. Effects of advertising news value may differ between very and medium important advertising clients as also suggested by Choi and Park (2011) and Hagen et al. (2014). Ideally, a future study could additionally distinguish between periods of overall increasing and decreasing advertising income and potentially resulting variance of obsequious journalism. Also, the present study as well as previous research are measuring advertising budget based on ad-page volume. Estimations based on ad-pages does not equal the net advertising income of a news outlet due to volume discounts that are not traceable for researchers. Thus, the actual importance of advertising clients for each news outlet may vary from the measurement used in this study. A second limitation concerns the assessment of the dimension of copy paste journalism. This study ignores other PR and strategic communication material besides press releases. Our findings do not reveal 
how much original journalistic work is included in an article and whether further material was used by journalists. We also have no information about the editorial situation in each newsroom or the relationship between business journalists and corporate news sources. Other forms of advertiser dutifulness such as reporting about a certain topic may exist (De Smet and Vanormelingen, 2011) but were not part of this study. Future research could consider further strategic communication material and triangulate content analyses with editorial interviews or ethnographic approaches including observations of editorial work to be able to provide a complete picture. As a third limitation, the number of press releases covered in news outlets was low especially for the tabloid $\mathrm{BaA}$, although focusing on all odd weeks of a whole year. However, enlarging the observation period in order to increase the number of press releases would strongly enlarge the total articles within the sample. Fourth, this study did not consider online news that were increasingly important for the considered news outlets. Yet we assume due to no online-first strategy of the news outlets that the print version comprises a more complete picture in 2012 than the online version. Finally, other industries that are covered in other sections, such as travelling, fashion or cosmetics, or other outlet types, such as magazines, may lead to other conclusions concerning advertiser value as suggested by Rinallo and Basuroy (2009).

\section{References}

An S and Bergen L (2007) Advertiser pressure on daily newspapers. Journal of Advertising 36(2): $111-121$. 
Anderson W and Lowrey W (2007) What factors influence control over work in the journalism/public relations dynamic? An application of theory from the sociology of occupations. Mass Communication and Society 10(4): 385-402.

Baerns B (2003) Separating advertising from programme content: The principle and its relevance in communications practice. Journal of Communication Management 8(1): 101-112.

Beam RA (2003) Content differences between daily newspapers with strong and weak market orientations. Journalism \& Mass Communication Quarterly 80(2): 368-390.

Boyer D (2013) The Life informatic: Newsmaking in the digital era. Ithaca: Cornell University Press.

Brierley S (2006) The advertising handbook. London: Routledge.

Choi J and Park S (2011) Influence of advertising on acceptance of press releases. Public Relations Review 37(1): 106-108.

Cornelissen J (2011) Corporate communication: A guide to theory and practice. Thousand Oaks, CA: Sage Publications.

Cotter C (2010) News talk: Investigating the language of journalism. Cambridge: Cambridge University Press.

Davis A (2000) Public relations, business news and the reproduction of corporate elite power. Journalism 1(3): 282-304.

De Smet D and Vanormelingen S (2011) Advertiser pressure on newspaper journalists: A survey. Available at: https://lirias.hubrussel.be/bitstream/123456789/5217/3/11HRP37.pdf (accessed 7 May 2015).

Dix S and Phau I (2009) Spotting the disguises and masquerades: Revisiting the boundary between editorial and advertising. Marketing Intelligence \& Planning 27(3): 413-427.

Eilders C (1997) Nachrichtenfaktoren und Rezeption: Eine empirische Analyse zur Auswahl und Verarbeitung politischer Information. Opladen: Westdeutscher Verlag.

Eilders C (2006) News factors and news decisions: Theoretical and methodological advances in Germany. Communications: The European Journal of Communication Research 31(1): 5-24.

fög (2013) Qualität der Medien: Jahrbuch 2013. Basel: Schwabe.

Fretwurst B (2008) Nachrichten im Interesse der Zuschauer: Eine konzeptionelle und empirische Neubestimmung der Nachrichtenwerttheorie. überarbeitete Dissertation an der FU Berlin 2008. Konstanz: UVK.

Galtung J and Ruge MH (1965) The structure of foreign news. Journal of Peace Research 2(1): 64 91.

Gambaro M and Puglisi R (2015) What do ads buy?: Daily coverage of listed companies on the Italian press. European Journal of Political Economy 39: 41-57.

Hagen LM, Flämig A and In der Au A (2014) Synchronisation von Nachricht und Werbung: Wie das Anzeigenaufkommen von Unternehmen mit ihrer Darstellung im Spiegel und im Focus korreliert. Publizistik 59(4): 367-386.

Hamilton JT (2004) All the news that's fit to sell: How the market transforms information into news. Princeton, NJ: Princeton University Press. 
Hanitzsch T and Mellado C (2011) What shapes the news around the world? How journalists in eighteen countries perceive influences on their work. International Journal of Press/Politics 16(3): 404-426.

Harcup T and O'Neill D (2001) What is news?: Galtung and Ruge revisited. Journalism Studies 2(2): 261-280.

Hong SY (2008) The relationship between newsworthiness and publication of news releases in the media. Public Relations Review 34(3): 297-299.

Hujanen J (2009) Informing, entertaining, empowering. Journalism Practice 3(1): 30-45.

Jackson D and Moloney K (2015) Inside churnalism. Journalism Studies: 1-18.

Kepplinger HM and Ehmig SC (2006) Predicting news decisions. An empirical test of the twocomponent theory of news selection. Communications 31(1): 25-43.

Kiousis S, Popescu C and Mitrook M (2007) Understanding Influence on Corporate Reputation: An Examination of Public Relations Efforts, Media Coverage, Public Opinion, and Financial Performance From an Agenda-Building and Agenda-Setting Perspective. Journal of Public Relations Research 19(2): 147-165.

Kolb S and Woelke J (2010) Einfluss von Werbekunden auf redaktionelle Inhalte: Quasi-experimentelle Modellierung und empirische Erhebung. Studies in Communication Sciences 10(2): 51-77.

Larsson L (2009) PR and the media. Nordicom Review 30(1): 131-147.

Lewis J, Williams A and Franklin B (2008) A compromised fourth estate? Journalism Studies 9(1): $1-20$.

Maat HP and Jong Cd (2013) How newspaper journalists reframe product press release information. Journalism 14(3): 348-371.

Maier M and Ruhrmann G (2008) Celebrities in action and other news news factors of German TV news 1992 - 2004: Results from a content analysis. Human Communication 11(1): 197-2014.

McManus JH (2009) The commercialization of news. In: Wahl-Jorgensen K and Hanitzsch T (eds) The handbook of journalism studies. New York: Routledge, pp. 218-235.

Media Focus (2012) Werbemarkt Trend Report 2012/05. Available at: http://www.werbewoche.ch/sites/werbewoche.ch/files/imce/shared/mediafocus_4.pdf (accessed 4 June 2016).

Nyilasy G and Reid LN (2011) Advertiser pressure and the personal ethical norms of newspaper editors and ad directors. Journal of Advertising Research 51(3): 538-551.

Obermaier M, Koch T and Riesmeyer C (2015) Deep impact?: How journalists perceive the influence of public relations on their news coverage and which variables determine this impact. Communication Research.

Picard RG (2001) Effects of recessions on advertising expenditures: An exploratory study of economic downturns in nine developed nations. Journal of Media Economics 14(1): 1-14.

Picard RG (2004) Commercialism and newspaper quality. Newspaper Research Journal 25(1): 5465. 
Pienegger A (2004) Public Relations und Wirtschaftsjournalismus: Eine Studie über Image und Akzeptanz der PR im Wirtschaftsjournalismus. In: Altmeppen K, Röttger U and Bentele G (eds) Schwierige Verhältnisse: Interdependenzen zwischen Journalismus und PR. Wiesbaden: VS Verlag, pp. 143-160.

Reich Z (2011) Different practices, similar logic: Comparing news reporting across political, financial, and territorial beats. The International Journal of Press/Politics 17(1): 76-99.

Reich Z and Godler Y (2014) A time of uncertainty. Journalism Studies 15(5): 607-618.

Reuter J and Zitzewitz E (2006) Do ads influence editors?: Advertising and bias in the financial media. The Quarterly Journal of Economics 121(1): 197-227.

Rinallo D and Basuroy S (2009) Does advertising spending influence media coverage of the advertiser? Journal of Marketing 73(6): 33-46.

Schafraad P and van Zoonen W (2015) Do news factors in corporate press releases influence the way journalists treat these press releases? Cardiff, UK.

Schafraad P, van Zoonen W and Verhoeven P (2015) The news value of Dutch corporate press releases as a predictor of corporate agenda building power. Public Relations Review.

Schweiger W and Jungnickel K (2011) Pressemitteilungen 2.0 - eine Resonanzanalyse im Internet. Publizistik 56(4): 399-421.

Seletzky M and Lehman-Wilzig S (2010) Factors underlying organizations' successful press release publication in newspapers: Additional PR elements for the evolving 'press agentry' and 'public information' models. International Journal of Strategic Communication 4(4): 244266.

Shoemaker PJ (2006) News and newsworthiness: A commentary. Communications 31(1).

Shoemaker PJ and Cohen AA (2006) News around the world: Content, practitioners, and the public. New York: Routledge.

Stiftung Werbestatistik Schweiz (2013) Werbeaufwand Schweiz 2013. Available at: http://www.werbestatistik.ch/download.php?id=37_188068aa (accessed 4 June 2016).

Stiftung Werbestatistik Schweiz (2016) Werbeaufwand Schweiz 2016. Available at: http://www.werbestatistik.ch/download.php?id=72_0c4d11e4 (accessed 4 June 2016).

Sumner DE (2001) Who Pays for Magazines? Advertisers or Consumers? Journal of Advertising Research 41(6): 61-67.

Swiss National Bank (2014) Banks in Switzerland 2014: List of reporting institutions. Available at: http://www.snb.ch/en/mmr/reference/bvbilsums_2014/source/bvBilsums_2014.en.xlsx (accessed 4 February 2016).

Tellis GJ and Tellis K (2009) Research on advertising in a recession: A critical review and synthesis. Journal of Advertising Research 49(3): 304-327.

van der Wurff R, Bakker P and Picard RG (2008) Economic growth and advertising expenditures in different media in different countries. Journal of Media Economics 21(1): 28-52.

van Hout T, Pander Maat H and Preter W de (2011) Writing from news sources: The case of Apple TV. Journal of Pragmatics 43(7): 1876-1889. 
Weaver DH, Beam RA, Brownlee BJ, Voakes PS and Wilhoit GC (2007) The American journalist in the 21st century: US news people at the dawn of a new millennium. Mahwah, NJ: Lawrence Erlbaum. 
Table 1: Sample of covered press releases

\begin{tabular}{|c|c|c|c|c|c|c|c|}
\hline \multirow{2}{*}{$\begin{array}{l}\text { Bank }^{\mathrm{a}} \\
\text { Big banks }\end{array}$} & \multirow{2}{*}{$\begin{array}{c}\text { Press re- } \\
\text { leases }\end{array}$} & \multicolumn{6}{|c|}{ Covered press releases } \\
\hline & & \multicolumn{2}{|c|}{$N Z Z$} & \multicolumn{2}{|c|}{$T A$} & \multicolumn{2}{|c|}{$B a A$} \\
\hline UBS & 19 & 19 & $100 \%$ & 19 & $100 \%$ & 17 & $89 \%$ \\
\hline Credit Suisse & 15 & 15 & $100 \%$ & 15 & $100 \%$ & 7 & $47 \%$ \\
\hline \multicolumn{8}{|l|}{ Smaller banks } \\
\hline Raiffeisen Bank & 5 & 4 & $80 \%$ & 4 & $80 \%$ & 2 & $40 \%$ \\
\hline Julius Bär & 10 & 9 & $90 \%$ & 8 & $80 \%$ & 3 & $30 \%$ \\
\hline Migros Bank & 3 & 2 & $67 \%$ & 3 & $100 \%$ & 0 & $0 \%$ \\
\hline Valiant Bank & 9 & 6 & $67 \%$ & 5 & $56 \%$ & 1 & $11 \%$ \\
\hline UBP & 3 & 0 & $0 \%$ & 0 & $0 \%$ & 0 & $0 \%$ \\
\hline Bank Coop & 6 & 2 & $33 \%$ & 1 & $17 \%$ & 0 & $0 \%$ \\
\hline Total & 70 & 57 & $81 \%$ & 55 & $79 \%$ & 30 & $43 \%$ \\
\hline
\end{tabular}

Notes. a) Sorted (descending) by balance sheet total. 
Table 2: Banks' relative advertiser importance per news outlet in 2012

\begin{tabular}{|c|c|c|c|c|c|c|}
\hline & \multicolumn{2}{|c|}{$N Z Z$} & \multicolumn{2}{|c|}{$T A$} & \multicolumn{2}{|c|}{$B a A$} \\
\hline & Adv in- & Relative ad- & Adv in- & Relative ad- & Adv in- & Relative ad- \\
\hline & come in & vertiser im- & come in & vertiser im- & come in & vertiser im- \\
\hline & thousand & portance & thousand & portance & thousand & portance \\
\hline & $\mathrm{CHF}$ & & $\mathrm{CHF}$ & & $\mathrm{CHF}$ & \\
\hline$\overline{\mathrm{UBS}}$ & 741 & $1.43 \%$ & 87 & $0.11 \%$ & 13 & $0.03 \%$ \\
\hline Credit Suisse & 3,814 & $7.35 \%$ & 263 & $0.32 \%$ & 0 & $0.00 \%$ \\
\hline Raiffeisen Bank & 10 & $0.02 \%$ & 58 & $0.07 \%$ & 104 & $0.23 \%$ \\
\hline Julius Bär & 802 & $1.54 \%$ & 448 & $0.54 \%$ & 0 & $0.00 \%$ \\
\hline Migros Bank & 0 & $0.00 \%$ & 11 & $0.01 \%$ & 0 & $0.00 \%$ \\
\hline Valiant Bank & 0 & $0.00 \%$ & 0 & $0.00 \%$ & 0 & $0.00 \%$ \\
\hline UBP & 0 & $0.00 \%$ & 0 & $0.00 \%$ & 0 & $0.00 \%$ \\
\hline Bank Coop & 0 & $0.00 \%$ & 0 & $0.00 \%$ & 0 & $0.00 \%$ \\
\hline
\end{tabular}

$\overline{\text { Notes. Gross advertising income. Relative importance relates to total gross advertising }}$ income per news outlet. NZZ realized a total gross advertising income of $51.9 \mathrm{~m} \mathrm{CHF}$, TA $82.8 \mathrm{~m} \mathrm{CHF}$, and $B a A 44.8 \mathrm{~m} \mathrm{CHF}$ in 2012. (Source: Mediafocus) 
Table 3: Estimation results

\begin{tabular}{|c|c|c|c|c|c|c|c|c|c|c|c|c|}
\hline & \multicolumn{3}{|c|}{ Degree of adoption } & \multicolumn{3}{|c|}{ Article size } & \multicolumn{3}{|c|}{ Article placement } & \multicolumn{3}{|c|}{ Article tone } \\
\hline & $\mathrm{NZZ}$ & TA & $\mathrm{BaA}$ & $\mathrm{NZZ}$ & TA & $\mathrm{BaA}$ & NZZ & TA & $\mathrm{BaA}$ & NZZ & TA & $\mathrm{BaA}$ \\
\hline \multicolumn{13}{|c|}{ Press release } \\
\hline \multirow[t]{2}{*}{ Reach } & 4.215 & -1.912 & -.0787 & 67.653 & $123.737 *$ & -24.874 & -3.182 & .950 & .626 & -.039 & -.026 & .226 \\
\hline & $(5.540)$ & (5.359) & (1.935) & (84.733) & $(52.502)$ & $(25.353)$ & $(2.335)$ & $(2.491)$ & (1.175) & $(.128)$ & $(.147)$ & $(.276)$ \\
\hline Positive & -.039 & $-7.434^{\circ}$ & 1.413 & -26.206 & -30.427 & 7.377 & .668 & -1.636 & -.777 & .135 & .081 & -.021 \\
\hline consequ. & (3.968) & (3.827) & $(1.390)$ & $(60.693)$ & $(37.493)$ & $(18.208)$ & $(1.539)$ & $(1.548)$ & $(.848)$ & $(.085)$ & $(.091)$ & (.199) \\
\hline Negative & $7.173^{*}$ & 1.895 & .420 & -52.669 & 23.060 & 7.607 & -.262 & -.186 & -.077 & -.051 & -.029 & -.177 \\
\hline consequ. & (3.579) & $(3.495)$ & $(1.255)$ & $(54.736)$ & $(34.240)$ & $(16.450)$ & $(1.470)$ & (1.477) & $(.693)$ & $(.081)$ & $(.087)$ & $(.163)$ \\
\hline Promi- & -.894 & 3.521 & $2.562 *$ & -.055 & -9.087 & 16.419 & -.874 & -1.655 & -.287 & -.058 & .030 & -.168 \\
\hline nence & (2.973) & (2.846) & (1.024) & $(45.467)$ & $(27.886)$ & (13.418) & (1.095) & (1.065) & $(.453)$ & $(.060)$ & $(.063)$ & $(.106)$ \\
\hline \multicolumn{13}{|l|}{ Receiver } \\
\hline Importance & -25.58 & 222.14 & 1855.6 & 1201.15 & $48542.9 * * *$ & 21067.3 & -4.49 & -972.9 & -917.9 & 2.078 & -19.70 & $409.94^{\circ}$ \\
\hline of $\mathrm{adv}$. & (103.93) & $(1285.5)$ & $(1420.3)$ & (1589.4) & (12593) & $(18610)$ & (38.95) & $(634.3)$ & (949.2) & $(2.142)$ & (37.37) & $(222.0)$ \\
\hline Source & & & & & & & & & & & & \\
\hline
\end{tabular}




\begin{tabular}{|c|c|c|c|c|c|c|c|c|c|c|c|c|}
\hline Balance & $-0.252 * *$ & $-0.153^{*}$ & 0.025 & $2.450^{\circ}$ & $3.200 * * *$ & $2.290 * * *$ & 0.040 & $-0.093 * *$ & $-0.040^{\circ}$ & -0.003 & 0.000 & -0.001 \\
\hline sheet total & (0.090) & $(0.075)$ & $(0.027)$ & (1.370) & $(0.731)$ & $(0.354)$ & $(0.034)$ & $(0.031)$ & $(0.020)$ & $(0.002)$ & $(0.002)$ & $(0.005)$ \\
\hline \multicolumn{13}{|l|}{ (in 10 bn) } \\
\hline \multirow[t]{2}{*}{ Constant } & -.281 & 32.452 & -4.462 & 264.94 & -125.83 & 29.278 & $38.827 * * *$ & $42.107 * * *$ & $10.343 *$ & -.065 & -.299 & -.403 \\
\hline & (17.595) & (17.238) & (5.951) & (269.08) & (168.88) & (77.969) & $(7.258)$ & (7.978) & $(3.675)$ & $(.399)$ & $(.470)$ & $(.862)$ \\
\hline$F$ & $2.56^{*}$ & 1.28 & $2.05^{\circ}$ & 1.60 & $8.53 * * *$ & $8.23 * * *$ & 0.69 & $2.91 *$ & 0.97 & 1.03 & 0.23 & 1.51 \\
\hline Adj. $R^{2}$ & 0.119 & 0.024 & 0.084 & 0.0498 & 0.396 & 0.3862 & -0.034 & 0.175 & -0.007 & 0.003 & -0.093 & 0.096 \\
\hline $\mathrm{n}$ & 70 & 70 & 70 & 70 & 70 & 70 & 57 & 55 & 30 & 57 & 55 & 30 \\
\hline
\end{tabular}

Notes. OLS estimates. Standard errors in parentheses. $* * * p<.001, * * p<.01, * p<.05,{ }^{\circ} p<.10$.

$\mathrm{n}=70$ press releases with and without coverage for each news outlet. $\mathrm{n}_{N Z Z}=57, \mathrm{n}_{T A}=55, \mathrm{n}_{B a A}=30$ press releases with coverage. 
NEWS ABOUT NEWSPAPER ADVERTISERS 